\title{
Discussion on the Construction of Experimental Technical Team of Higher Engineering Education under the Background of "Double First- class" Construction
}

\author{
Jianyong Li, Jianfeng Li ${ }^{*}$, Zhaoliang Jiang, Zhenjie Zhu \\ National Experimental Teaching Demonstration Center for Mechanical Foundation, School of Mechanical Engineering, Shandong Unive \\ rsity, Jinan 250061, China \\ Email: ljf@sdu.edu.cn
}

\begin{abstract}
Double first-class" construction is a major strategic plan made by China in the new historical period. Under this background, this paper analyzes the main problems existing in the construction of the experimental technical team in higher engineering education, such as inadequate understanding, inadequate management, inadequate incentive, and inadequate guarantee. It studies the construction of experimental technical team from four aspects: management methods, a personnel introduction and mobility mechanism, evaluation and incentive methods and construction and training measures. Based on the idea of "four-dimension integration" innovation-driven post-performance, "three levels and two categories" experimental technical team construction scheme of higher engineering education is put forward.
\end{abstract}

Keywords: double first-class, engineering education, experimental technology, team construction

\section{Introduction}

To build world-class universities and first-class disciplines is a major strategic deployment made by China in the new historical period. The main carrier of higher engineering education is colleges and universities. Colleges and universities can't build "double first-class" without laboratories. To build a first-class high-level laboratory is an objective requirement for promoting the construction of "double first-class". If colleges and universities want to produce first-class achievements and cultivate first-class talents, they must have a first-class laboratory and experimental technical team ${ }^{[1]}$.

As the backbone of laboratory construction and development, laboratory technicians play an irreplaceable role in experimental teaching, scientific research, personnel training, and laboratory construction and management ${ }^{[2]}$. The definition of laboratory technical team in colleges and universities is not unified by the state, such as the working regulations of laboratories in colleges and universities (1992) and the measures for the construction and operation management of key laboratories of the Ministry of Education (2015). They are different in the definition of experimental staff. So far the Ministry of Education has not issued a programmatic document specifically for the establishment and construction of experimental technical teams in colleges and universities, and colleges and universities rarely put forward specific construction plans for the development of experimental technical teams. The quality, development and standardized management of the experimental technical team are seriously affected ${ }^{[3]}$.

Under the background of "double first-class" construction, this paper analyzes the main problems existing in the construction of the experimental technical team in higher engineering education, such as inadequate understanding, management, incentive, and guarantee. And the writer studies the construction of experimental technical team from four aspects: management methods, personnel introduction, and flow mechanism, evaluation and incentive methods, the construction of training measures, then proposes a project of "four-dimensions integration" innovation-driven postperformance and "three-levels and two-types" experimental technical team construction in higher engineering education (Figure 1). Four dimensions are management method, a personnel introduction, and mobility mechanism, evaluation and incentive method, the construction of training measures; three levels are school, department and college; two types are experimental technical post and experimental management post; one is to promote stability and sustainable development. On this basis, this paper emphasizes the role of innovation drive and post-performance in constructing an experimental technical team in higher engineering education. 


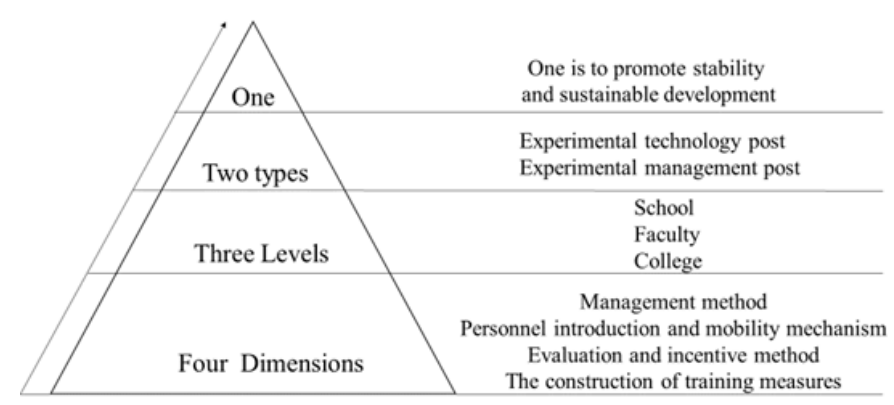

Figure 1. The plan of "four-dimensions integration" innovation-driven post-performance and "three-levels and two-types" experimental technical team construction in higher engineering education

\section{Current situation of experimental technical team construction}

\subsection{Understanding of experimental technical team construction}

Colleges and universities lag in the construction of the experimental technical team. They pay insufficient attention to it, and the construction of the experimental technical team lacks long-term mechanisms. Experimental technicians have been in the ranks of the "teaching assistants" ${ }^{[4]}$. The experimental technicians are defined as "teaching assistant" series, which is easy to form a misunderstanding. They think that this team is replaceable and less demanding, so anyone can do it. It is considered that the work assessment is difficult to quantify, and the work is easy, so their remuneration should be lower. Chinese colleges and universities generally attach great importance to the construction and management of teaching and scientific research team, while the management of the experimental technology team is seriously inadequate. There is a lack of strong policy guidance in the aspects of the establishment of accounting, personnel introduction, professional title promotion, post-appointment, and assessment, and it is difficult for high-level experimental technicians to develop stably and sustainably.

Problem analysis: inadequate understanding. According to institutions of higher learning, experimental technicians are defined as "teaching assistants" series. Compared with teachers, the construction of experimental technicians is not important, and they lack construction funds and overall planning. The construction of "double first-class" requires the competent authorities to fully understand the position of the experimental technical team in the university, and the construction plan of the experimental technical team should be issued as soon as possible.

\subsection{Management of experimental technical team}

In the current management system of colleges and universities, there are many problems in laboratory management. The training and funds for experimental technicians are managed by the personnel department; the laboratory environment construction is managed by the logistics support department; the laboratory equipment and daily work are managed by the asset and laboratory management department; the experimental teaching is managed by the undergraduate and graduate schools; the daily operation of the laboratory is managed by the secondary college. The laboratory has at least five direct leading units ${ }^{[5]}$.

Problem analysis: management is not in place. Multiple management is easy to appear some problems, such as the experimental technology team construction mutual prevarication and no attention to it. If the post responsibilities are not clear, the difference of laboratory types are ignored, and all laboratory personnel is classified into one category, which will easily lead to a series of problems, such as unclear responsibilities, no problems and no questions, and vague assessment standards. So that some irresponsible people will be involved in the experimental team for a long time. It is very important to establish the management method of experimental personnel, which includes post setting, post responsibility, a personnel introduction, and flow mechanism.

\subsection{Evaluation and incentive of an experimental technical team}

It is difficult to quantify the performance evaluation of university laboratories, and the evaluation system of laboratory technicians is more difficult. At present, most of the experimental technicians in colleges and universities lack a strict index system for evaluation, assessment, and employment. Some of the performance evaluation is mainly based on the opinions of the heads of departments. This evaluation system has a strong subjective assumptions and insufficient scientific basis ${ }^{[6]}$. In addition, there are few incentive measures for the experimental technical team, which frustrates the enthusiasm of the experimental technical team and finally makes it difficult to promote the overall development and promotion of the 
experimental technical team.

Experimental technicians spend a lot of time on the construction and management of the laboratory. But the results of laboratory construction and the cultivation of students' abilities are difficult to quantify and the workload is relatively low. In some schools, the allowance of experimental technicians is obviously low, the treatment of experimental technicians and related policies can't be solved for a long time, and laboratory jobs are not attractive. Compared with the full-time teachers, the experimental technicians have fewer opportunities in the promotion, evaluation, honor, and awards ${ }^{[7]}$.

Problem analysis: The incentive is not in place. The assessment standard overemphasizes the workload of experimental teaching and the number of scientific research tasks. For that excellent experimental personnel based on their own posts, who focus on experimental design and development, an innovation of experimental means and methods, application and development of sophisticated experimental equipment, are not recognized and effectively encouraged. Their work performance is ignored. Moreover, there are few opportunities to evaluate and reward. Therefore, it is necessary to improve the assessment and incentive mechanism, promote the construction of the laboratory management technical team in colleges and universities.

\subsection{Construction training of experimental technical team}

In order to attract and retain high-skilled talents, colleges and universities also set up positions for researchers according to their positions and actual needs. Although there are promotion and development channels for a professional title, it is still difficult for laboratory technical personnel with deputy high titles to be promoted to researchers ${ }^{[8]}$. In the initial stage of entering the experimental technical team, because of the starting point of grading is the same, the salary is basically the same as other staff in the teaching team, with no obvious difference. However, with the later evaluation and appointment of professional titles, the number of senior positions in the experimental technical posts in most colleges and universities is rare, and the deputy senior level is almost the "ceiling" of development, which leads to a gradual widening of the salary gap between the experimental technology post and other positions in the teaching team, and at the same time, the payment of subsidies for other posts further increases the income gap ${ }^{[9]}$.

Problem analysis: the guarantee is not in place. Experimental technicians have fewer opportunities for further study, training and technology upgrading, which directly affects the updating of knowledge structure and technical skills. How to improve the theoretical accomplishment and skill level of experimental technicians, motivate their work enthusiasm and team spirit, is an urgent and extremely difficult task in the construction of a university laboratory management technical team.

\section{Discussion on specific construction scheme}

This paper proposes a new scheme, which based on "four-dimensions integration" innovation-driven postperformance and "three-levels and two-types" experimental technical team construction in higher engineering education It covers management measures, a personnel introduction, and mobility mechanism, evaluation and incentive measures, construction and training measures. It can support experimental service teaching and scientific research, so as to improve the laboratory opening level and utilization rate of the experimental equipment. And it will provide a theoretical reference for the promotion in the whole school.

\subsection{Research on management method of an experimental technical team}

\subsubsection{Post setting scheme}

In view of the present situation of an experimental technical team of higher engineering education college, the experimental technology team will be sorted out within two years ${ }^{[10]}$. According to the principle of "total amount control, post setting as required and overall planning", on the premise of not breaking through the overall scale of teaching assistant team, on the one hand, through scientific post setting, clear post responsibilities to promote internal post adjustment; on the other hand, through diversified employment forms, further supplement the experimental technical team.

On the basis of respecting the history, the number of experimental posts is determined by comprehensively considering factors such as organization scale, discipline setting, equipment quantity, teaching and scientific research volume, and serviceability. At the same time, experimental (teaching) center, public service platform, instrument, and equipment management, safety management and other factors are taken into consideration ${ }^{[1]}$.

Configuration of experimental technology team $(1+\mathrm{N}+\mathrm{x})$ : 1Laboratory directors $+\mathrm{N}$ laboratory technicians $+\mathrm{X}$ flexible employees as required. 


\subsubsection{Post classification (Table 1 )}

Table 1. Post classification of an experimental team

\begin{tabular}{cc}
\hline Job category & Detailed post \\
\hline $\begin{array}{c}\text { Experimental technology } \\
\text { post }\end{array}$ & Researcher \\
& $\begin{array}{c}\text { Senior experimenter / Senior Engineer } \\
\text { Experimenter / Engineer }\end{array}$ \\
\hline Assistant experimenter / Assistant Engineer \\
\hline Experiment management & Laboratory director \\
post & Device administrator \\
& Security personnel, etc. \\
\hline
\end{tabular}

KPI system introduction and diagnosis analysis of team building

Key performance indicators (KPI) are the basis of work performance management to decompose long-term objectives into operational work objectives tools. By setting, quantifying and analyzing the key parameters of the construction of the experimental technology team, a kind of objectively quantified management index to measure the process performance is formed(in Table 2 and Figure 2).

Table 2. List of KPI index system

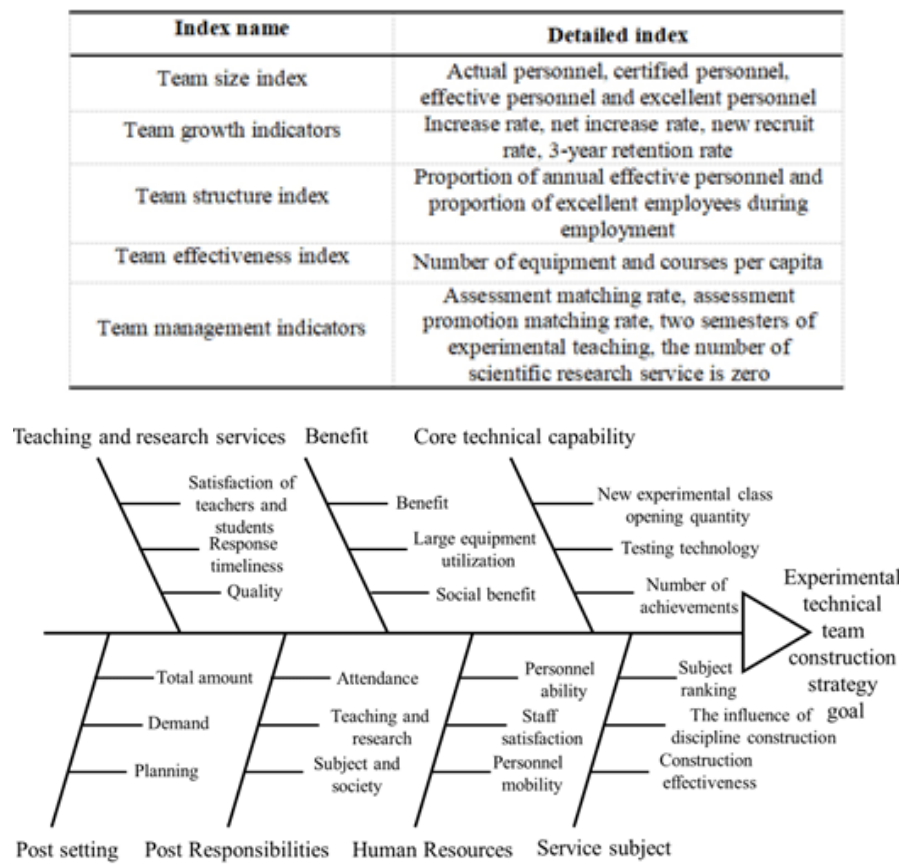

Figure 2. KPI indicators based on experimental posts and processes - FAST analysis (fish bone diagram)

\subsection{Research on the mechanism of personnel introduction and flow}

Strengthen the assessment of the employment period based on post responsibilities, and sort out the existing experimental technology team and experimental management team. The personnel working in the experimental post must be actually engaged in the work of experimental technology, experimental teaching or laboratory construction, and management. For the original engineering experimental post personnel who fail to perform the corresponding post responsibilities, they will be separated through a job transfer, low employment, and short employment. After a certain transition period, they will leave school or continue to hire. At the same time, teachers engaged in experiment related work are encouraged to transfer to the experimental technology team ${ }^{[12]}$.

\subsection{Research on evaluation incentive measures}

\subsubsection{Assessment and evaluation}

The objective, fair and scientific assessment, and evaluation mechanism should be established and improved. The evaluation methods and indexes of experimental technicians should be beneficial to the improvement of experimental teaching level and experimental technical ability ${ }^{[13]}$. Assessment and evaluation contents include professional ethics, work attitude, professional ability, technical development, practical skills, work performance and performance, evaluation of teachers, students and users, attendance, etc. The assessment is divided into annual assessment and employment period 
assessment. The assessment of the employment period based on post responsibilities will be strengthened ${ }^{[14]}$.

\subsubsection{Salary distribution}

The salary of the staff in public institutions is mainly based on the allocation of school resources, and the employer should supplement it appropriately. The salary of the project employees shall be borne by the specific employer. The determination and adjustment of the salary distribution of the laboratory staff should refer to the development of the laboratory construction, the laboratory assessment, the individual performance, and other factors. It is suggested that the school should timely improve the relevant treatment of excellent experimental technicians.

\subsubsection{Post allowance}

The implementation method of the post allowance distribution system should be further improved. On the basis of considering the key performance appraisal indicators, distribution principles that promote stable and sustainable development should be considered.

\subsubsection{Honor and award}

On the basis of the evaluation of the existing advanced laboratory workers and advanced collective, we will set up the experimental technology achievement award, and gradually improve the incentive measures for the experimental technology team. Through project funds and awards for honorary achievements, experimental technicians are encouraged to engage in experimental equipment research, experimental technology development, and experimental teaching reform.

\subsection{Research on construction training measures}

\subsubsection{Professional and technical post promotion}

Improve the professional and technical post promotion system of the experimental series, and timely revise the implementation measures for the appointment of professional and technical posts of the experimental series.

\subsubsection{Professional and technical post level adjustment}

To establish the platform and mechanism conducive to the personal development of the experimental technical team and improve its career development channel and space. In the implementation rules for the employment of the existing professional and technical positions, further, refine the promotion conditions for the professional and technical positions of the experimental series, and timely set up a talent growth plan for the experimental technical team ${ }^{[15]}$.

\subsubsection{Specialized training}

Training is an important basis for the appointment of professional and technical positions of experimental technicians. Personnel department and asset management and laboratory department jointly organize a series of training for laboratory technicians, including professional quality, business theory, practice ability, laboratory safety management, and management practice training. KPI indicators based on a balanced scorecard can analyze the causal relationship between key success factors and performance indicators in the learning and growth of experimenters (Figure 3).
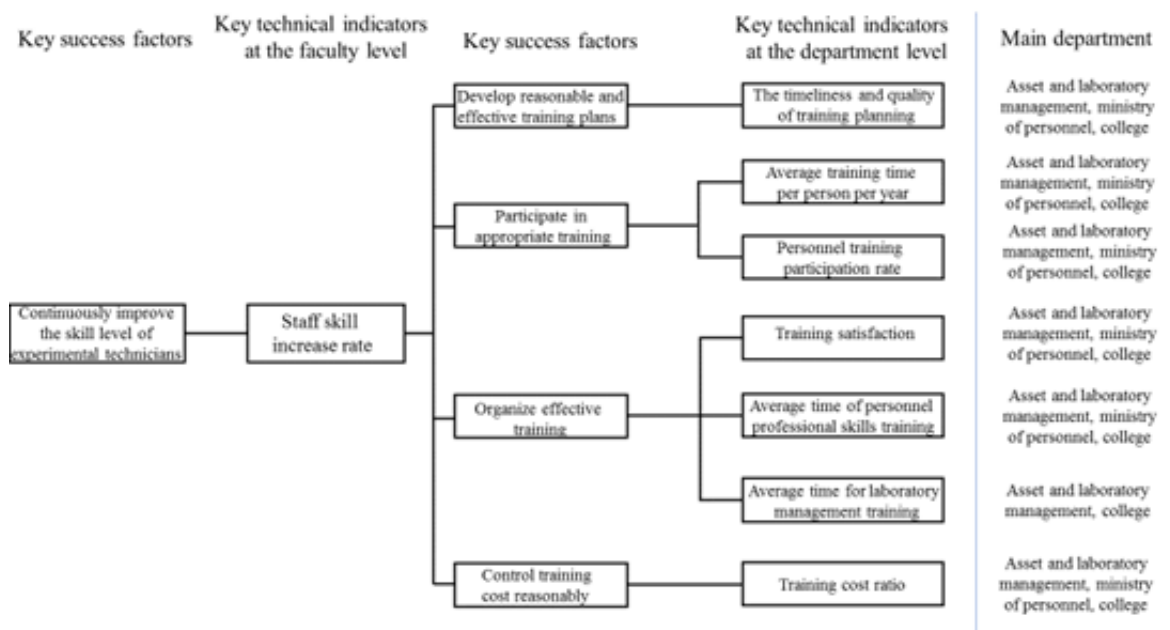

Figure 3. KPI indicators based on Balanced Scorecard: causal relationship model between key success factors and performance indicators in learning and growth

\section{Conclusion}

Under the background of "double first-class" construction, considering the rationality, operability and popularization 
of system reform, system construction and policy-making, this paper puts forward the construction plan of "three levels and two categories" higher engineering education experimental technology team driven by "four dimensions in one" innovation, so as to fill the policy gap of the country in this field. The experimental technology team construction and promotion mechanism of "point, line, and surface" combination can provide a reference for college pilot, Department demonstration and school promotion.

By using the key performance index method in human resource management, the key parameters of the experimental technology team are set, quantified and analyzed, the problems in the construction of the experimental technology team are diagnosed, and the feasible management methods, personnel introduction flow mechanism, evaluation incentive methods and construction training measures of the experimental technology team in higher engineering education are formulated, so as to improve the opening level of the laboratory utilization rate of instruments and equipment.

This paper constructs the KPI indicators based on the Balanced Scorecard - the causal relationship model between the key success factors in learning and growth and performance indicators, which provides a theoretical method for the research of construction training measures.

\section{Acknowledgments}

This work was supported by the fund of education and teaching reform research, Shandong University (2019y100,F 2 019y112, 2019y113). We especially acknowledge all of the people who have contributed to our research. Conflict of intere st statement: the authors declare no competing financial interests.

\section{References}

[1] Jin Shengju. On constructing the first-class laboratory to promote the "dual-class" development. The Science Education Article Cultures. 2016; (24): 51-52.

[2] Du Qing, Chen Jianwei. Improving laboratory management in scientific institutions by opening and sharing. Research \& Exploration in Laboratory. 2014; 33(4): 233-236.

[3] Chen Lan, Yang Jinglun, Liu Lixun. Exploration and practice of experimental teaching reform in independent colleges: based on the perspective of training applied talents. Experimental Technology \& Management. 2015; (8): 176178.

[4] Xie Qiuli, Zhang Yun. Improve the assessment and incentive mechanism to promote the construction of the laboratory management technology team in colleges and universities. Education and teaching forum. 2017; (52): 13-14.

[5] Chen Xiangbin. Suggestions for the construction and development of the experimental technology team in Colleges and universities. Laboratory research and exploration. 2016; 35(12): 260-262.

[6] Zhou Xuebing, Xu Lei, Chen Rongxu. Construction and management of laboratory technical team in Colleges and universities. Laboratory research and exploration. 2015; 34(2): 243-245.

[7] Zhang Jianhua, Wang Yanji. Research on the construction of the technical team of computer room management in Colleges and universities. Experimental technology and management. 2017; 34(5): 226-228.

[8] Lei Jianlan, Xuan Ying, Tang Wei, et al. Countermeasures for the construction of large-scale instrument experimental technology team. Experimental technology and management. 2016; 33(5): 237-239.

[9] Xu Hao. (2014) Research and practice of common problems in university laboratory construction and management. Master's Thesis, Hefei University of Technology, Hefei.

[10] Wei Wei. Countermeasures for the assessment mechanism of experimental technicians in Colleges and universities. Laboratory research and exploration. 2011; 30(12): 157-161.

[11] Lu Guibin, Hou Xinchun, Ying Anming. Strengthening the construction of the experimental technology team in Colleges and universities. Experimental technology and management. 2007; 24(12): 164-167.

[12] Li Jinhui, Zhang Ke, Li Xiaohui, et al. (2012) The thinking of strengthening the team construction of college experimental teachers. In: Wu Y. (eds) Advanced Technology in Teaching - Proceedings of the 2009 3rd International Conference on Teaching and Computational Science (WTCS 2009). Advances in Intelligent and Soft Computing, vol 116. Springer, Berlin, Heidelberg. https://doi.org/10.1007/978-3-642-11276-8_117.

[13] Zhao Yan, Cheng Yuanli. Strengthening the construction of the experimental technology team and promoting stable and sustainable development. Experimental science and technology. 2016; 14(6): 242-245.

[14] Zhang Jinbiao, Zhu Zhengguo, Gao Yuxin. Thoughts on the construction of the experimental technology team in colleges and universities. Research on laboratory work in Colleges and universities. 2013; (3): 53-54.

[15] Zhao Yang, Guan Liping, Li Haiyan, et al. Exploration and thinking on the construction of the experimental technology team in research universities. Research on laboratory work in universities.2015; (4): 70-72. 